is established, so that this whole process represents good value for money and effort.

Indira Vinjamuri Specialist Registrar in Adult Mental Illness, address supplied, email: vinjamuriindira@nhs.net

\section{Additional drug use on methadone programmes - often cocaine rather than heroin}

It was interesting to see the issue of whether dosage of methadone affected the use of additional drugs raised in the Bulletin most recently by Kernan \& Scully (Psychiatric Bulletin, June 2006, 30, 234) Although many clinicians are reluctant to prescribe high doses of methadone, the evidence does seem clear that heroin use tends to decline as methadone increases.

This is a substitution approach, but patients on methadone programmes can develop as many problems from ongoing cocaine as from heroin use (notably financial and psychiatric problems). This appears to be widespread (Gossop et al, 2002), and in two related investigations of our own patients undergoing opioid substitution ( $n=57$ and $n=72$ ) cocaine was used by many of the $77 \%$ of patients showing some additional drug in their urine. Abstinence from substance use was related to female gender $\left(\chi^{2}=0.62\right.$, d.f. $=1$, $P<0.1)$, type of substitute medication $\left(\chi^{2}=6.8\right.$, d.f. $\left.=2, P<0.05\right)$ and being longer in treatment $(t=1.61, P<0.1)$, but for overall drug use the dosage of maintenance agent had no effect. For cocaine this was one of the weakest relationships $\left(\chi^{2}=0.2\right.$, d.f. $\left.=1, P>0.1\right)$.

Outcomes in maintenance treatment are usually related to limiting heroin use, and the fallback measure of increasing methadone to achieve this has been attractive. We believe that the frequent use of cocaine among this population will render methadone treatment much less straightforward, with more requirements for additional behavioural treatments (Schottenfeld et al, 2005).

GOSSOP, M., MARSDEN, J., STEWART, D., et al (2002) Changes in use of crack cocaine after drug misuse treatment: 4-5 year follow-up results from the National Treatment Outcome Research Study (NTORS). Drug and Alcohol Dependence, 66, 21-28.

SCHOTTENFELD, R., CHAWARSKI, M., PAKES, J., et al (2005) Methadone versus buprenorphine with contingency management or performance feedback for cocaine and opioid dependence. American Journal of Psychiatry, 162, 340-349.

*Nicholas Seivewright Consultant Psychiatrist in Substance Misuse, The Fitzwilliam Centre, 143-145 Fitzwilliam Street, Sheffield S1 4JP, email: alayna.maurer@sct.nhs.uk, Liz Horsley Pre-registration House Officer, Sheffield,

Kelly Gadsby Medical Student, Sheffield

\section{Changing role of the junior psychiatrist - implications for training}

Imagine the daily life of the junior psychiatrist in the not too distant past: clerking of new admissions to the ward day or night; physical examinations and routine phlebotomy; providing a service to the general hospital for psychiatric emergencies, including overdose assessments; reviewing the patients' mental state in the clinic and prescribing medication; responding to requests from nursing staff manning the wards when all others are sleeping.

How the life of the junior doctor has changed! The first to go was routine phlebotomy, closely followed by a variety of other tasks which are now performed by non-medical professionals whose roles are ever increasing. As highlighted by Woodall et al (Psychiatric Bulletin, June 2006, 30, 220-222), liaison assessments are increasingly being carried out by specialist nursing staff, with an inevitable effect upon the experience gained by senior house officers. The driving force behind this remains unclear. The European Working Time Directive has been implicated in these changes, but the other more cynical view is that doctors' time is more costly than that of nursing and auxiliary staff.

With nursing staff taking on prescribing, triaging of emergency calls and assessment in all settings and at all hours, what are the doctors left with? How ironic that junior doctors who no longer perform these roles as part of their training will very soon, with the introduction of the run-through grades, be supervising the practice of these highly experienced non-medical professionals.

*Louise Cooke Senior House Officer in Child Psychiatry, 4th Floor, Bridgewater House Blackpole Road, Worcester WR4 9GG, email: louisecooke@yahoo.com,

Louisa James Specialist Registrar in General Adult Psychiatry, Crisis Resolution and Home Treatment, Bridgewater House, Worcester

Woodall et al (Psychiatric Bulletin, June 2006, 30, 220-222) describe how the introduction of nurse-led liaison services has left senior house officers (SHOs) with little to do on call. Senior house officers are left with routine ward work while nurses become skilled at emergency psychiatric assessment. The original purpose of the changes was to leave some of the simpler tasks to nurses, freeing the SHOs to carry out work traditionally considered to require a doctor. The pendulum has now swung too far, with specialist nurses taking over increasing amounts of doctors' work.

These changes resulted from the implementation of the European Working
Time Directive after vociferous protest by earlier generations of SHOs over poor pay and excessive working hours. The government, for financial reasons, was happy to heed these protests and has implemented these changes at a time when the length of postgraduate training is being reduced by the Modernising Medical Careers initiative.

The remedies proposed by Woodall et al are primarily bureaucratic and will take valuable time to implement. A more prompt and practical remedy would be for SHOs to return to where they belong, in the acute clinical front line, alongside their specialist nursing colleagues. Evaluation of the efforts of both, using audit systems already in place, would provide a useful opportunity to test the fundamental and as yet unanswered question that lies behind the current changes: do doctors have more to offer than nurses in the assessment and management of acute psychiatric emergencies?

Chloe Beale East London and the City Mental HealthTrust, Homerton Hospital, London E9 6SR, email: chloe.beale@elcmht.nhs.uk

Woodall et al (Psychiatric Bulletin, June 2006, June 2006, 30, 220-222) highlight the potentially adverse effects on the clinical experience of psychiatric trainees of increased reliance on liaison nurses to conduct emergency psychiatric assessment. As members of the liaison team in the hospital in Wrexham where the study was conducted, we would like to respond.

Liaison psychiatry, in particular the assessment of patients after self-harm, offers excellent opportunities for trainees to develop a range of clinical skills, including rapport in difficult circumstances, comprehensive history-taking and mental state examination, case formulation, risk assessment, negotiating a management plan with the patient and communicating effectively with all parties.

We wholeheartedly support the development of the role of liaison nurses because it increases capacity and improves service delivery. However, we are concerned about the effect that this might have on the clinical experience of psychiatric trainees. Hence for some time we have invited trainees to voluntarily undertake psychosocial assessments jointly with liaison nurses. However, the uptake of this offer has been variable and this latest study has underlined the need for a new approach.

With the consensus of consultant colleagues, all junior psychiatrists will now be required to complete ten joint psychosocial assessments every 6 months in addition to their on-call work. They will observe the first few assessments while the liaison nurse takes the lead, and then take the lead on the remaining assessments. Trainees will also continue to 